\title{
What kind of food policy?
}

\section{Colin Blythe and Howard Rush examine whether nutritional goals can be a basis for agricultural policy}

PARTICIPANTS at a number of recent conferences in Britain have tried to clarify the links between nutritional requirements, food production and supplies. Titles of meetings reflect the interest: 'People and Food Tomorrow', 'Towards a Healthier Britain' and, most recently, 'Nutritional Aspects of Food and Agricultural Policy in the United Kingdom'. All have raised a number of scientific, ethical and practical problems, and it has become apparent that until these are resolved little progress towards one coherent policy, integrating nutritional considerations, food supplies and agricultural production, seems possible. It is even argued that British policy makers remain unconvinced of the need for such a policy. What are the main arguments?

The possibility of malnutrition in some low-income groups has occasioned some concern. Clinical evidence of deficiencies is not common, however, except in certain welldefined groups, and where deficiency malnutrition exists, it is seldom due to simple poverty. Low levels of vitamin $\mathrm{D}$ and associated rickets occur in parts of the UK Asian community. Osteomalacia and vitamin $C$ deficiency (not necessarily together) are found in a proportion of the elderly. Iron deficiency anaemia is said to affect about $10 \%$ of women in the UK, and folate deficiency (showing as megaloblastic anaemia of pregnancy) has occurred recently in about $2.5 \%$ of women. Deficiencies of other micronutrients may occur but the number of affected individuals is small.

In contrast, reports and papers dealing with the 'diseases of affluence' are growing more numerous; since 1970 nearly twenty reports have come from national bodies on the subject of coronary heart disease alone. As well as cardio- and cerebro-vascular disease, the list includes diverticulitis, appendicitis, constipation, certain forms of colonic cancer and, with its numerous sequelae (backache, arthritis of knees and hips, gallstones, renal failure and fallen arches), obesity.

The consensus of opinion in these reports is that some aspects of Western diet are partly responsible for the present levels of these diseases. Most conclude that wholesale changes in

Colin Blythe is at the Department of Nutrition, Queen Elizabeth College, London.

Howard Rush is at the Science Policy Research Unit, University of Sussex. diet are necessary before the major causes of illness and premature death are brought under control. The US Senate Select Committee on Nutrition and Human Needs, under Senator McGovern, has recently promulgated a set of Dietary Goals: these include a reduction of total fat intake (within which there should be a decrease in the proportion of saturated fats and an increase in the proportion of polyunsaturated fats), a reduction in dietary cholesterol, sugar and salt, and an increase in consumption of complex carbohydrates. Sweden has had a Diet and Exercise Programme, incorporating similar goals, since 1972. Norway recentiy announced its intention to use pricing policy as well as education in an attempt to influence eating habits.

\section{Evidence contested}

Unfortunately, the factual evidence underlying goals of this type is contested. Disagreements over both causation and remedial measures are one reason. They have meant that the connection between diet and disease is not yet strong enough in the minds of UK policy makers for them to accord nutrition a priority in economic decisions. But having no policy amounts, in reality, to a policy of letting things drift, something which is clearly unsatisfactory. And the World Health Organisation said in 1969 that the incidence of certain diseases (coronary heart disease, for example) had reached almost "epidemic proportions".

The issues of causation may not have been resolved by clinical procedures, but then many of the tests needed to establish a causal relationship can only be performed on live human beings, and large numbers of them at that. Absolute proof may be years in coming. In the absence of absolute proof, this demands the exercise of scientific judgment based upon the best information avilable. Whether to wait for final proof (one way or the other), or whether to advise action now, is something which presents nutritionists with difficulties of judgment and also of conscience.

In Britain, the existing government role concerning diet is primarily one of monitoring, testing and education. In addition, $a$ web of legislation governing food standards, additives, labelling and advertising has evolved largely on an ad hoc basis. Policy questions, such as whether Britain should or could feed itself, usually turn

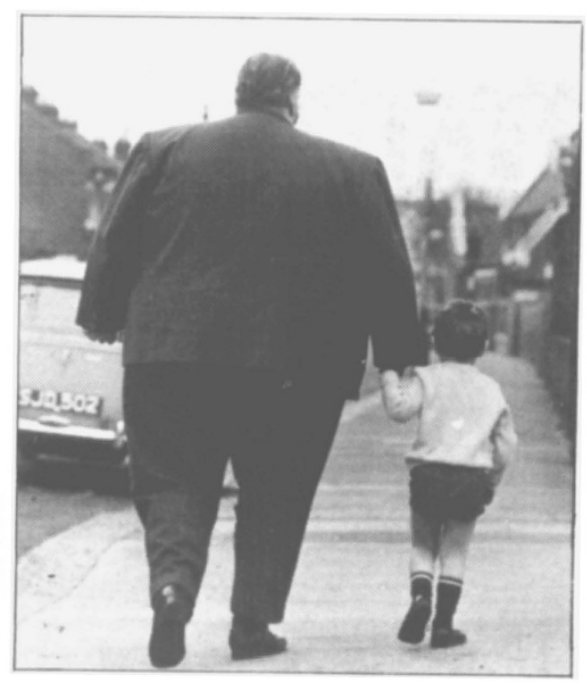

upon issues of security of supplies and the balance of payments. Seldom, if ever, are variations in food supplies or self-sufficiency levels related to their possible effects on the nutritional status of the population. Nor would it seem that nutritional considerations have prompted recent government interventions in food prices. Mollifying consumer unrest, assisting the economically disadvantaged and dealing with farm surpluses have been of greater concern.

The lack of nutritional reasoning behind adjustments to food supplies and prices does not, however, mean that such moves lack nutritional impact. EEC policy, for instance, is to reduce the price of certain items currently in over-supply, like butter, in order to stimulate demand, increase consumption and clear the surplus. Beyond boosting consumption artificially, this produces a secondary effect: the tendency to maintain isocaloric balance means that, as consumption of some foods rises, consumption of other items falls. In other words, by manipulating food prices for basically agricultural purposes, governments can apparently exert an effect on eating patterns and, unwittingly, on nutritional status. As recent EEC policy has sought to encourage consumption of some items which epidemiological evidence has linked with disease, the anxiety of many nutritionists to see nutritional criteria built into food policy becomes understandable.

\section{Basis for policy?}

But if the factual evidence underlying nutritional goals is controversial, so is the advisability of using them as the basis of policy. Government intervention in dietary matters is a hotly contested issuc. Among nutritionists a sizeable lobby believes that the scale of diet-related discase is such as to justify a far more radical approach to public health. This group would like to see 
pricing and educational measures employed as part of a coherent policy of trying to prevent ill health, rather than attempting to cure the results of unwise living. A shift to preventive medicine is economically attractive. Although few figures are available for Britain, recent estimates put the total costs to the US economy of heart disease and other diet-related illness at between \$30-35 billion annually. Costs to the UK economy must also be considerable. It may be that prices of alcohol, tobacco and some food items should more accurately reflect the community health costs incurred by their overconsumption.

A national programme of preventive medicine would almost certainly involve individuals assuming greater responsibility for their own health and basing their actions on adequate information. Attempts to educate the public on dietary matters, however, have a poor record of success. If changes are to occur in consumption levels public education may need to be reinforced with food price adjustments. Such procedures would have to be thought out with great care. Some evidence exists for suggesting that sub. sidies do not always benefit target groups as intended. So if taxes are also to be used to persuade consumers to alter their habits, steps will have to be taken to ensure the adequacy of diets among low-income groups.

Opponents of blanket government measures belicve that improved screening and diagnosis are all that is required. After diagnosis, those at risk can take remedial action and those unaffected can escape being troubled or inconvenienced by wholesale measures. This view contends that, although nutritional needs can be assessed case-by-case, prescribing aver-

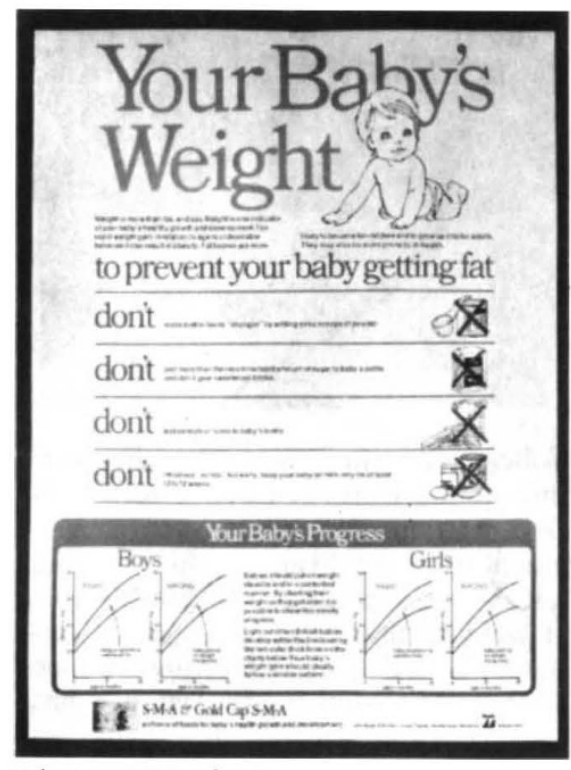

age requirements for entire populations on present knowledge is premature, and might even endanger some people's health. In discouraging overconsumption, it is asked, how is discrimination avoided against those who are not overconsuming, or those who, if they are at risk at all, may be at risk from under- rather than over-nutrition? And even if causation could be proved and remedial measures agreed, what of the freedom of individual choice? Is it for governments to coerce people into taking measures for their own good?

In the end, other factors may dictate the best course of action-the state of the economy, for example, or the adequacy of diagnostic facilities and personnel. Identifying every individual at risk of heart disease or stroke would involve a major programme of screening, with those placed in the 'at risk' category being examined at, say, yearly intervals, the rest perhaps every four or five years. Such a programme would add greatly to the costs of a Health Service already widely regarded as economically burdensome.

\section{Disagreements}

This discussion of means obscures the fact that no policy maker can be expected to act until a basis for action has been agreed. Unfortunately, there are strong disagreements over appropriate remedial measures. One example of conflicting advice to the government lies in recent evidence to the UK House of Commons Expenditure Committee considering preventive medicine. In this, the British Dietetic Association suggested that "a moderate reversal to diets in which bread and potato consumption are increased would be an advantage"; the British Medical Association felt that "the right diet for

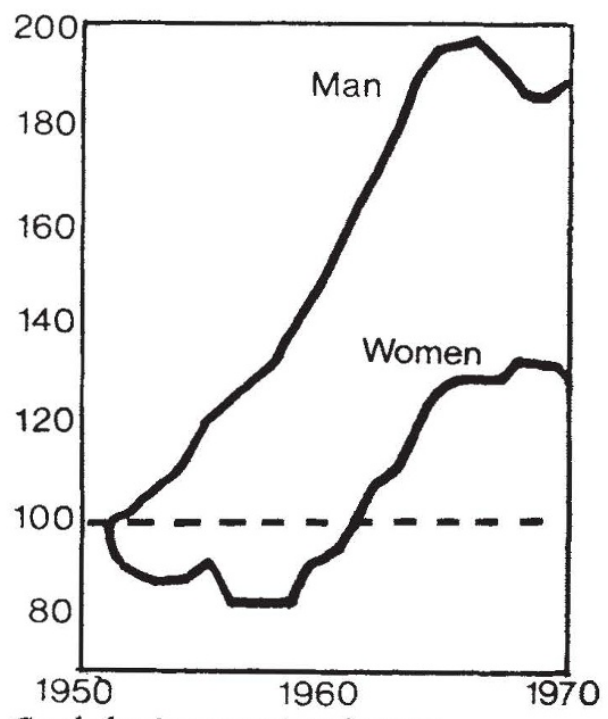

Graph showing percentage increase in death rates due to coronary heart disease of men and women in England and Wales in 35-44 age group optimal weight was relatively high in fat, high in protein and low in carbohydrates". Such advice is just as confusing to individuals who wish to follow sensible eating regimes.

The quality and relevance as public guidelines of some other information is also open to doubt. Tools long accepted for evaluating nutritional status, such as the Recommended Daily Intake (RDI) tables, have begun to be questioned. Should the RDIs relate to a level of intake designed to secure optimum health (a concept in itself difficult to define), or to a level necessary to avoid the onset of illness? If the latter then, given that nutrient requirements vary not only for age and sex but also for bodyweight and metabolic type, illness for whom? The question of how much information now available can usefully be applied in constructing diets is also relevant. For example, is the RDI of $30 \mathrm{mg}$ vitamin $C$ per day for an adult to be secured by eating one tomato, or two? If minimum nutrient requirements cannot be assessed except on a caseby-case basis, if the notion of an 'optimal' intake is unscientific, and if the RDI tables offer no guidance on the designing of meals, what useful purpose is served by such information?

All these general problems have meant that governments have received little in the way of useful advice regarding the effect of agricultural policy on nutrition, although the fact that agricultural policy can influence nutrition is not seriously disputed. Clearly, when the major problems within nutrition are sorted out, it will be time for some cross-fertilisation to take place between disciplines. At a conference organised by the Nutrition Society in Reading recently, one example did emerge of the type of thinking that may be required to bridge the agriculture/nutrition gap.

In it, Professor W. Holmes briefly suggested some changes and problems facing UK agriculture if food goals outlined by the US Senate and others are to be realised. For example, an increase in the contribution of bread grains, vegetables and fruit to the diet, and a reduction in the intake of animal products (especially animal fats), might require a correspanding increase in the arable area and a reduction in the use of grain for animal feed. Though noting that such a change was technically feasible, he pointed out the considerable effects on the cost and profitability of farming and on the ancillary industries. A detailed study of the complex components within the farming community and of the incentives and advice necessary to achieve improvements was necessary, before any attempt to implement a food policy was likely to be successful. 